\title{
A STUDY OF ASSOCIATION OF ABO BLOOD GROUP TYPES AND ABH SECRETOR STATUS IN PATIENTS OF TYPE II DIABETES MELLITUS IN KADAPA DISTRICT
}

\author{
Parveen $S^{1}$, A. Chandra Sekhar ${ }^{2}$
}

${ }_{1}^{1}$ Assistant Professor, Department of Physiology, RIMS, Kadapa, Andhra Pradesh, India.

${ }^{2}$ Associate Professor and HOD In-charge, Department of Physiology, RIMS, Kadapa, Andhra Pradesh, India.

ABSTRACT
BACKGROUND
Diabetes Mellitus (DM) is a syndrome characterized by hyperglycaemia resulting from defects of insulin secretion and/or increased
cellular resistance to insulin. Diabetes Mellitus is a common medical problem having significant morbidity and mortality. It has a
genetic predisposition, although environmental factors do play a role in its genetic expression. Like many other inherited traits, ABH
secretor status is also genetically pre-determined and therefore may have an association with diabetes mellitus.
Aims \& Objectives- The study was done to determine whether there is any association between ABO blood group types and ABH
secretor status with type II diabetes mellitus.

\section{MATERIALS \& METHODS}

A cross sectional study was performed on 200 patients of type II diabetes mellitus diagnosed based on Accu-Chek glucometer method after taking detailed history and informed consent. This is a case-control study and selection of cases and controls was done by simple random sampling. 200 control group population who are non-diabetic were taken from Blood Bank, RIMS, Kadapa. ABO blood grouping was done by slide agglutination method in both cases and control groups and secretor status was determined by indirect haemagglutination method in both cases and control groups. Chi-square test and p value were used for statistical analysis through SPSS software version 17.

\section{RESULTS}

Out of 200 diabetic patients, 65 (32.5\%) were secretors and 135 (67.5\%) were non-secretors. While in control group 150 (75\%) were secretors and $50(25 \%)$ were non-secretors. Non-secretors were significantly associated with diabetes than secretors $\left(X^{2}=72.6587, d f=1, p\right.$ value $\left.=0.000\right) . A B O$ blood group types are not significantly associated with Diabetes Mellitus $\left(X^{2}=7.7073, d f=3\right.$, $\mathrm{p}$ value $=0.0523$ ). Females were more prone to diabetes (142 out 200), but there is no significant association with the gender $\left(X^{2}=0.3518, \mathrm{df}=3\right.$, $\mathrm{p}$ value $\left.=0.95\right)$.

\section{CONCLUSION}

The study concludes that there was significant association between secretor status proving that non-secretors are more prone to diabetes than secretors. B group females 52 (36.6\%) were more prone to diabetes when compared to other blood group types and males. There was no significant association between ABO blood groups and diabetes mellitus. Hence, we need larger sample size to prove the association.

\section{KEY WORDS}

ABO Blood Group, ABH Antigens, Secretors, Non-Secretors, Diabetes Mellitus.

HOW TO CITE THIS ARTICLE: Parveen S, Sekhar AC. A study of association of ABO blood group types and ABH secretor status in patients of type II diabetes mellitus in Kadapa district. J. Evolution Med. Dent. Sci. 2018;7(52):5524-5529, D0I: $10.14260 /$ jemds/2018/1223

\section{BACKGROUND}

At the turn of the 20th century, Karl Landsteiner first described the existence of serological differences between individuals and stated that people of the world, irrespective of their race can be divided into four groups depending on the substances present on the surface of their red blood cells. In 1901, he grouped the individuals into $\mathrm{A}, \mathrm{B}, \mathrm{AB}$ and $\mathrm{O}$. The discovery of the iso-agglutinogens was a mile stone in the field of medicine. Karl Landsteiner received the Nobel prize for his discovery of the $\mathrm{ABO}$ system of blood groups.(1)

'Financial or Other Competing Interest': None.

Submission 22-08-2018, Peer Review 10-12-2018,

Acceptance 17-12-2018, Published 24-12-2018.

Corresponding Author:

Dr. A. Chandra Sekhar,

Associate Professor and HOD In-charge,

Department of Physiology,

RIMS, Kadapa, Andhra Pradesh, India.

E-mail: sekharphysiology@gmail.com

DOI: $10.14260 /$ jemds/2018/1223

(c) $(7)$
The A, B and 0 genes all locate together at 9q34.1-q34.2. the genes of the ABO system do not encode directly for the antigens but encode for enzymes that add specific sugars to the red cell membrane. These sugars are the ABO red cell antigens that are detectable with serological testing. The ' $A$ ' gene codes for the transferase alpha $\mathrm{N}$-acetyl-galactosaminyl transferase and the ' $\mathrm{B}$ ' gene codes for transferase alpha galactosyl transferase and ' $\mathrm{O}$ ' allele encodes for a non-functional transferase.(2)

The ABH antigens are found not only on red cells but also on other cells, in the most body fluids and on the cell membranes of tissues such as intestine, urothelium and vascular endothelium. The expression of $\mathrm{ABH}$ antigens into body fluids is controlled by the Sese genes and they are located on chromosome 19 q13.3.(3) The ability to secrete water soluble A, B and $\mathrm{H}$ antigens was found to be inherited in a Mendelian manner, genetically independent of genes controlling the expression of $\mathrm{ABO}$ blood group antigens on the surfaces of red cells. ABH secretion is controlled by two alleles, Se (Dominant) and se (Recessive). Individuals possessing the 
dominant allele either in homozygous or heterozygous situation (SeSe/sese) are termed as secretors, while homozygous recessive individuals (sese) are termed nonsecretors.(4)

The term ABH secretor refers to secretion of $\mathrm{ABO}$ blood group antigens in fluids such as saliva, sweat, tears, semen and serum. Approximately $80 \%$ of the people are secretors (SeSe or sese). People who do not secrete their blood type antigen in their secretions are termed non-secretors. About $15 \%$ of the population are non-secretors. For example-

1. O Group secrete $\mathrm{H}$ antigen.

2. A group secrete $A$ and $H$ antigen.

3. B group secrete $B$ and $H$ antigen.

4. AB group secrete $\mathrm{A}, \mathrm{B}$ and $\mathrm{H}$ antigen.(5)

Ever since the discovery of these antigens, there have been concerted efforts to discover a positive association between ABO (H) antigens and different disease conditions.(6) For example, increased H.pylori infection with increased duodenal ulcer, peptic ulcer disease and hyperpepsinogenemia,(7) thrombotic and heart disease, recurrent urinary tract infection, persistent candida infection, autoimmune diseases including ankylosing spondylitis, reactive arthritis, Grave's disease, Sjogren's syndrome, Psoriatic multiple sclerosis.(8)

Diabetes Mellitus is a syndrome characterized by hyperglycaemia resulting from defects of insulin secretion and increased cellular resistance to insulin. Diabetes Mellitus is generally divided as IDDM (Insulin dependent diabetes mellitus) or type I Diabetes Mellitus, characterized by an absolute deficiency of circulating insulin and NIDDM (Noninsulin dependent diabetes mellitus) characterized by elevated insulin levels that are ineffective in normalizing blood sugar levels or by impaired insulin secretion.(9) Type II Diabetes Mellitus is the most common type accounting for 90 $95 \%$ of all diabetic cases. $(10)$

\section{MATERIALS AND METHODS}

\section{Study Design/Method of study}

This is a case - control study which is a type of observational study. This study was conducted between March 2017 to March 2018 in RIMS General Hospital and the department of Physiology, at Kadapa district in Andhra Pradesh. Case sheets proforma were filled for type II Diabetes Mellitus patients and control non-diabetic subjects to obtain their medical history and socio-demographic parameters (Age, sex, educational status, occupation, blood groups and willingness to participate in the study)

\section{Method of Sampling}

Simple random sampling was used among cases and controls.

\section{Study Subjects}

The study included a total of 200 type II Diabetes Mellitus patients. Patients were selected at random who came to the diabetic clinic at RIMS General Hospital, Kadapa. The diagnosis of Diabetes Mellitus was done based on the Fasting Blood Glucose and Post Prandial Blood sugar level done by AccuChek glucometer. Among them 58 were males and 142 were females. Both males and females of ages ranging from 30-70 years were recruited.

\section{Control Subjects}

200 volunteer non-diabetic control subjects were recruited for this study from the Blood Bank, RIMS, Kadapa. Among them 120 were males and 80 were females both males and females of ages ranging from 30-70 years were recruited.

\section{Blood Group Determination}

Blood group is determined by Slide agglutination technique.

\section{Principle}

The surface of the red cell membrane contains genetically determined antigens, called agglutinogens, while plasma contains antibodies called agglutinins. To determine the blood group of a person, his/her red cells are made to react with sera containing agglutinins. The slide is then examined under a microscope, to detect the presence or absence of clumping and haemolysis of red cells, that occurs as a result of antigenantibody reaction.

\section{Materials}

Antisera, slide, lancet, compound microscope

\section{Procedure}

Under aseptic precautions, the pulp of the ring finger was pricked by a sterile lancet and one drop of anti-A was placed on one side of a microscopic slide and labelled as A. One drop of anti-B was placed, on the other side of the same slide and labelled as B. A drop of blood was added to each drop of antiserum. Blood groups were determined as follows-

1. Agglutination in slide A- Blood group A

2. Agglutination in slide B-Blood group $B$

3. Agglutination in both slides-Blood group $A B$

4. Agglutination in neither slide- Blood group $\mathrm{O}$

\section{Determination of Secretor Status}

It is determined by Hemagglutination inhibition technique.

\section{Principle}

If the blood group antigens are present in saliva, when an appropriate antiserum is added to it, an antigen -antibody reaction occurs. The antibodies in the serum neutralize the antigens in saliva. When a red cell suspension of the same blood group is now added to this mixture, there is no agglutination, due to previous inhibition of the antiserum. Thus, in the case of secretors there will be no agglutination seen. In the case of non-secretors, as their saliva does not contain blood group antigens, the antiserum added, will not be inhibited by the antigens. Now when the red cell suspension of the same blood group, is added to the mixture and there will be an agglutination reaction. Thus, in case of non-secretors, there will be agglutination.

\section{Materials}

1. $5 \%$ red cell suspension.

2. Antiserum (Anti-A, Anti-B, Anti-H)

3. Diluted and processed saliva.

4. Test tube rack with tubes.

5. Pipette.

6. Microscope.

7. Slide.

8. Centrifuge.

9. Hot water bath.

10. Sterile containers. 


\section{Procedure}

Saliva was collected at room temperature between 11 a.m. and 12 noon and tests were carried out, between 12 noon and 4 p.m.

\section{a) Preparation of $\mathbf{5 \%}$ Red Cell Suspension}

The freshly collected blood in an EDTA bottle, was transferred into a small glass tube and centrifuged at a speed of $3000 \mathrm{rpm}$, for 15 minutes, to pack the red cells. The supernatant plasma was separated as much as possible, from the cells and replaced by sterile isotonic saline. This mixture was centrifuged and again the supernatant separated from the cells. This procedure was repeated 3 to 4 times, to wash the red blood cells. Washing of the red blood cells was done to remove any antibody, present on the cells.

After the last washing, the supernatant was removed and one drop of packed red cells, was mixed with 19 drops of normal saline, to prepare a $5 \%$ red cell suspension in isotonic saline.

\section{b) Collection and Processing of Saliva}

Saliva was collected at room temperature in sterile, disposable containers. The patient was instructed to wash the mouth and drink a glass of water. One millilitre of saliva was collected in a sterile plastic bottle and transferred to a sterile test tube. The tube was then kept in a boiling water bath $\left(100^{\circ} \mathrm{C}\right)$, for twenty minutes. Saliva was boiled, to destroy the enzymes present. The saliva was then centrifuged at 3000 revolutions per minute (rpm), for fifteen minutes. The supernatant was separated and diluted in a 1:4 ratio. All the saliva samples were tested for secretor status, on the same day of their collection.

\section{c) Dilution of Anti-Serum}

Anti-A and Anti-B antisera were used for patients of blood group A and blood group B and Anti-H antisera was used, for patients belonging to blood group 0 . Antisera were diluted in a dilution of 1:8. e.g. if diluted anti-A was to be prepared, four test tubes were kept in a row and one drop of saline was put into each tube. One drop of Anti-A was now added to the first tube and mixed. Then one drop of diluted serum was taken from the first tube and added to the second tube. The same procedure was followed up to the fourth tube. (ref) as shown in the table below:

\begin{tabular}{|c|c|}
\hline Tube & Dilution \\
\hline Tube 1 & $1: 1$ \\
\hline Tube 2 & $1: 2$ \\
\hline Tube 3 & $1: 4$ \\
\hline Tube 4 & $1: 8$ \\
\hline
\end{tabular}

One drop of processed saliva and one drop of diluted antiserum from test tube four (1:8 dilution) were now added to fresh test tube.

\section{d) Procedure to determine Secretor Status}

The contents were mixed well and allowed to stand for fifteen minutes. Then a drop of standard red cell suspension was added and allowed to stand for sixty minutes. The mixed solution was examined under microscope. Care was taken to wash the pipette repeatedly, immediately after each dip. No agglutination suggested the presence of antigen in saliva, while agglutination suggested the absence of antigens in the saliva. Saline controls were kept simultaneously with the test.

\section{Method of Study}

The frequency distribution and prevalence of various parameters were determined by Chi-square test using SPSS software version 17 .

\section{RESULTS}

The study was done to find out that there is any correlation between $\mathrm{ABO}$ blood groups, secretor status \& the incidence of type II Diabetes Mellitus in Kadapa district. 200 type II Diabetes Mellitus patients (58 males and 142 females) and 200 controls (120 males and 80 females) subjects participated in the study.

A total of 65 (32.5\%) type II Diabetes Mellitus patients and $150(75 \%)$ control subjects were secretors while 135 (67.5\%) type II Diabetes Mellitus and 50 (25\%) control subjects were non-secretors. The frequency of ABH secretor status reported in the control subjects in this study is generally higher than what is obtainable worldwide where about $20 \%$ are nonsecretors. ${ }^{(11)}$

\begin{tabular}{|c|c|c|}
\hline Blood Groups & Males & Females \\
\hline A & 16 & 42 \\
\hline $\mathrm{B}$ & 20 & 52 \\
\hline $\mathrm{AB}$ & 6 & 12 \\
$\mathrm{O}$ & 16 & 36 \\
\hline Chi-square Value & \multicolumn{2}{|c|}{0.3518} \\
\hline 'p' value & \multicolumn{2}{|c|}{0.95} \\
\hline Table 1. Gender Wise Distribution of Cases
\end{tabular}

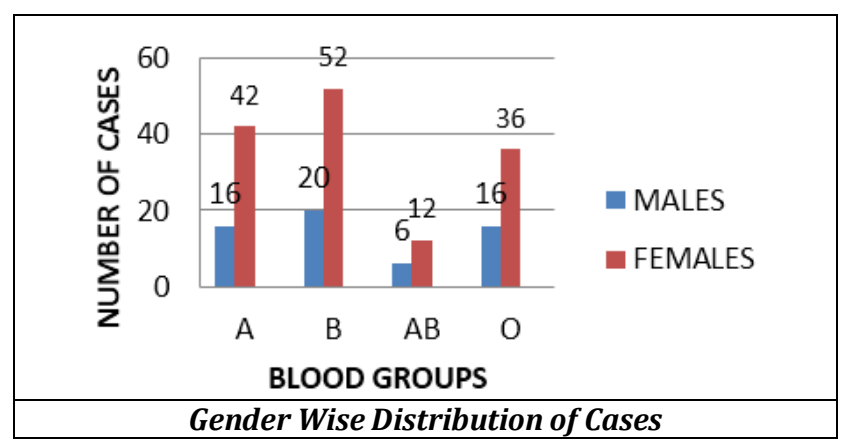

\begin{tabular}{|c|c|c|}
\hline Blood Groups & Males & Females \\
\hline $\mathrm{A}$ & 25 & 16 \\
\hline $\mathrm{B}$ & 42 & 28 \\
\hline $\mathrm{AB}$ & 5 & 8 \\
\hline $\mathrm{O}$ & 48 & 28 \\
\hline Chi-square value & \multicolumn{2}{|c|}{2.8449} \\
\hline 'p' value & \multicolumn{2}{|c|}{0.416} \\
\hline \multicolumn{2}{|c|}{ Table 2. Gender Wise Distribution of Controls } \\
\hline
\end{tabular}

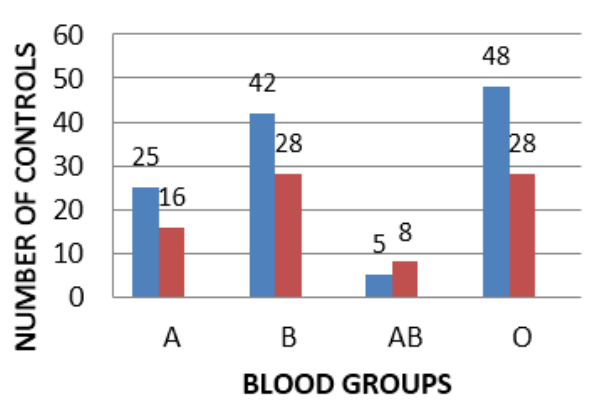

MALES FEMALES

Gender Wise Distribution of Controls 


\begin{tabular}{|c|c|c|}
\hline & Secretors & Non-Secretors \\
\hline Cases (200) & 65 & 135 \\
\hline Controls (200) & 150 & 50 \\
\hline Chi-square value & \multicolumn{2}{|c|}{72.6587} \\
\hline 'p' value & \multicolumn{2}{|c|}{0.000} \\
\hline Table 3. Distribution of Secretor Status among Cases and \\
Controls \\
\hline
\end{tabular}

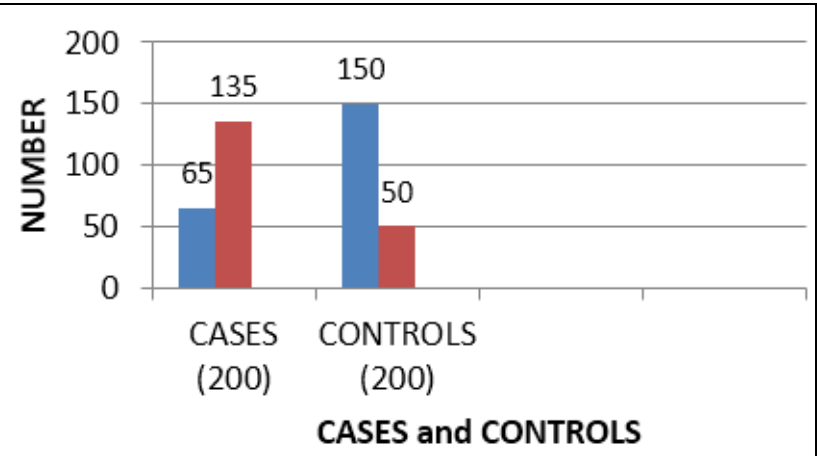

- SECRETORS NON SECRETORS

Distribution of Secretor Status among Cases and Controls

\begin{tabular}{|c|c|c|}
\hline Blood Groups & Secretors (65) & $\begin{array}{c}\text { Non-Secretors } \\
\text { (135) }\end{array}$ \\
\hline A & 8 & 12 \\
\hline $\mathrm{B}$ & 32 & 82 \\
\hline $\mathrm{AB}$ & 7 & 23 \\
\hline 0 & 18 & 18 \\
\hline Chi-square value & 7.7073 & \\
\hline 'p'value & 0.0523 & \\
\hline \multicolumn{3}{|c|}{ Table 4. Distribution of Secretor Status among Cases } \\
\hline
\end{tabular}

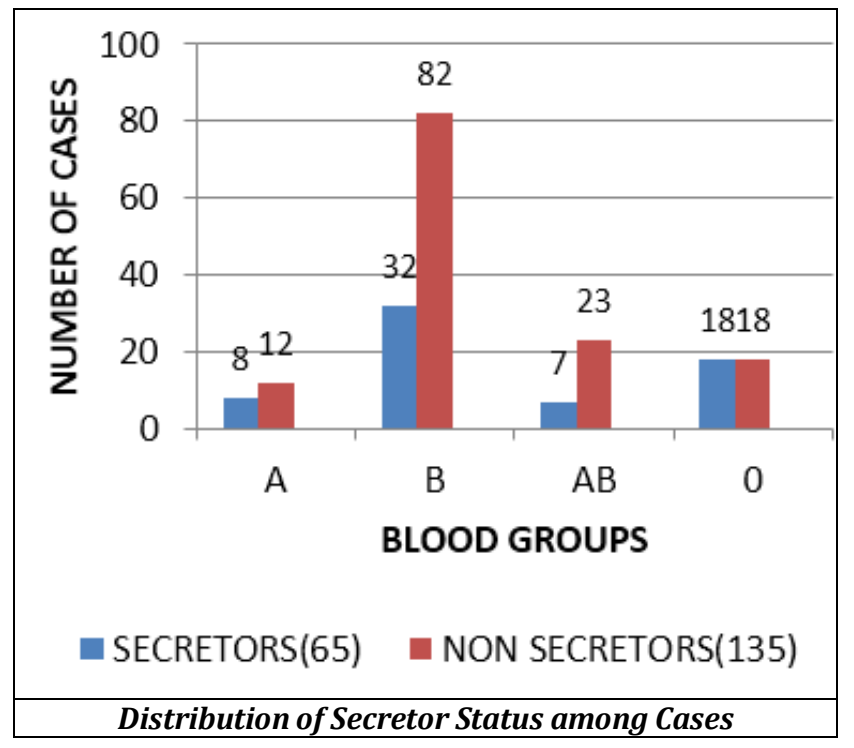

\begin{tabular}{|c|c|c|}
\hline Blood Groups & Secretors (150) & Non-secretors (50) \\
\hline $\mathrm{A}$ & 32 & 9 \\
\hline $\mathrm{B}$ & 38 & 12 \\
\hline $\mathrm{AB}$ & 18 & 7 \\
\hline 0 & 62 & 22 \\
\hline Chi-square value & 0.4134 & \\
\hline 'p' value & 0.9374 & \\
\hline
\end{tabular}

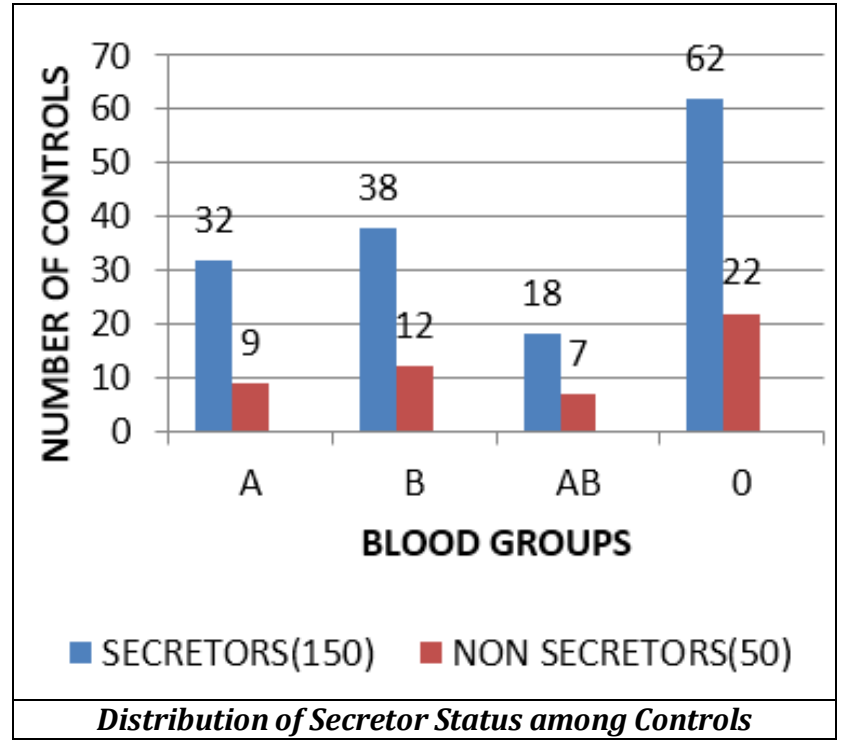

\section{DISCUSSION}

Igbenegher et al(12) reported a frequency of $75 \%$ secretors and $22 \%$ non-secretors in Osogbo in south-western Nigeria while Jaff( 13$)$ reported a frequency of $76 \%$ secretors and $23.9 \%$ nonsecretors in Iraq. Akhter et al(14) found a frequency of $\mathrm{ABH}$ secretor status of $60 \%$ and non-secretors of $40 \%$ in Dhakar.

In this study, more diabetic patients are non-secretors 135 (67.5\%) as compared to control subjects 50 (25\%). This is in accordance with the research carried out by Patrick and Collier(15) which states that $\mathrm{ABH}$ non- secretors, and especially Lewis negative individuals, are at a greater risk of developing diabetes (Especially adult onset diabetes), and they might be at a greater risk of developing complications from diabetes.

Even though much remains unclear concerning genetics and other factors involved in the aetiology of DM, it was earlier stated that a recessive gene present in double dose causes DM. However present studies do not rule out the possibility of multiple genes rather than a single pair of gene coupled with environmental factors as the major predisposing factors to DM.(16)

The FUT2 gene encodes fucosyl transferases that transfer a terminal fucose residue to a pre-existing precursor substance to form a soluble $\mathrm{H}$ antigen in secretor tissues, which serves as a precursor for soluble ABH antigens. Hence, individuals having at least one functional FUT2 allele, their $\mathrm{ABH}$ antigens are not only detected on their cell surfaces, but also in their body fluids including saliva. Non-secretors are homozygous for two inactive FUT2 alleles (SeSe). It is therefore possible that the presence of genes that predispose a person to DM may down regulate the expression of FUT2 (Secretor) gene and secrete enzymes, leading to the higher percentage of non-secretors in type II DM patients.(17)

The available data on association between the distribution of ABO blood types and DM is conflicting, some studies reporting no association while others showed positive association. Rahman(18) reported no significant association between ABO blood types and DM in a study from Bangladesh with a sample size of 2312 patients and 8939 controls. Koley(19) also reported no association between DM and ABO blood group types among Madhya Pradesh population in India. However Kamil et al(20) in Malaysia reported a positive association between ABO blood group types and DM with 
group $\mathrm{A}$ and $\mathrm{O}$ being more frequent among the controls than the diabetic subjects. Okon et al(21) also reported a positive association between $\mathrm{ABO}$ blood types and DM in south-eastern Nigeria where blood group $\mathrm{A}$ and $\mathrm{O}$ was found to be more frequent among the diabetics than the control subjects.

There is a strong relationship between blood group and diabetes risk with participants with the 0 blood type having a lower risk of developing type II diabetes. The researchers found that women who were blood group B positive were 35\% more likely to develop type II DM than those with blood group 0.(22) In Germany(23) and Glasgow(24) -there was no significant association between ABO blood groups and diabetes. Qureshi \& Bhatti found that $\mathrm{O}$ and $\mathrm{A}$ blood groups appear to be more frequent in healthy controls compared to type II DM patients.(25) An association of DM with blood group A was demonstrated by McConnell \& Pyke(26) and this was confirmed by Andersen and Lauritzen.(27) The study showed a significant excess of blood group A among male diabetics such as a combined series from Lancashire; Cheshire and Oxford.(26) There is increased frequency of blood group B among diabetics in studies from Trinidad (28) and Italy.(29)

\section{CONCLUSION}

The study concludes that there is a significant correlation between ABO blood types \& secretor status. The incidence of type II DM is more in B group non-secretors.

\section{Recommendations}

To reduce the risk, life style modifications like physical exercise, antioxidant rich diet like fruits, vegetables and polyunsaturated fats should be started at an early age to reduce the role of risk factors for ischemic heart disease as secretor status and ABO types are genetically determined.(30)

\section{REFERENCES}

[1] Schwarz HP, Dorner F. Karl Landsteiner and his major contributions to haematology. British Journal of Haematology 2003;121(4):556-65.

[2] abcd Entrez Gene: ABO blood group (transferase A, alpha 1-3-N-acetylgalactosaminyl transferase; transferase B, alpha 1-3-galactosyl transferase).

[3] Wisthoff CM, Reid ME. ABO and related antigens and antibodies. In: Hillyer, Silberstein, Ness, et al. eds. Blood banking and Transfusion Medicine (Basic principles and practice). $2^{\text {nd }}$ edn. USA: Churchill Livingstone/ Elsevier 2007: p. 69-79.

[4] Olorunshola KV, Audu L. ABO (H) secretor status of sickle cell disease patients in Zaria, Kaduna state, Nigeria. Niger J Physiol Sci 2013;28(1):29-34.

[5] Importance of secretor status. The Blood Type. Eat Right 4 your Type Diets.ww.dadamo.com.

[6] Waseem AG, Iqbal M, Khan OA, et al. Association of diabetes mellitus with $\mathrm{ABO}$ and Rh blood groups. Ann Pak Inst Med Sci 2012;8(2):134-6.

[7] Dickey W, Collins JS, Watson RG, et al. Secretor status and Helicobacter pylori infection are independent risk factors for gastroduodenal disease. Gut 1993;34(3):351-3.

[8] D'Adamo PJ, Kelly GS. Metabolic and immunological consequences of $\mathrm{ABH}$ secretor and Lewis subtype status. Alternative Medicine Review 2001;6(4):390405.
[9] American Diabetes Association. The diagnosis \& classification of diabetes mellitus. Diabetes Care 2004;27(Suppl 1):S5-S10.

[10] Harris MI, Hadden WC, Knowler WC, et al. Prevalence of diabetes and impaired glucose tolerance and plasma glucose levels in U.S. population aged 20-74 yr. Diabetes 1987;36(4):523-34.

[11] Dacie JV, Lewis SM. Practical haematology. $8^{\text {th }}$ edn. London: Churchill Livingstone 1994.

[12] Igbeneghu C, Odaibo GN, Olisekodiaka JM, et al. ABO blood group and secretor status in HIV infection in Osogbo, South-Western Nigeria. European Journal of Research in Medical Sciences 2015;3(1):1-7.

[13] Jaff MS. Higher frequency of secretor phenotype in 0 blood group - its benefits in prevention and/ or treatment of some diseases. Int J Nanomedicine 2010;5:901-5.

[14] Akhter S, Kibria GM, Akhter NR, et al. ABO and Lewis blood grouping with $\mathrm{ABH}$ secretor and non-secretor status: a cross sectional study in Dhaka. Faridpur Med Coll J 2011;6(1):38-40.

[15] Patrick AW, Collier A. An infectious aetiology of insulindependent diabetes mellitus? Role of the secretor status. FEMS Microbiol Immunol 1989;1(6-7):411-6.

[16] Gunther O. Etiology of Diabetes Mellitus. Abh Deutsch Akad Wiss Berlin 1960: No. 5.

[17] Rouquier S, Lowe JB, Kelly RJ, et al. Molecular cloning of a human genomic region containing the $\mathrm{H}$ blood group alpha $(1,2)$ fucosyl transferase gene and two $H$ locus related DNA restriction fragments. Isolation of a candidate for the human Secretor blood group locus. J Biol Chem 1995;270(9):4632-9.

[18] Rahman M. Non-association of ABO blood groups with diabetes mellitus in Bangladesh. Bangladesh Med Res Counc Bull 1976;2(2):144-6.

[19] Koley S. The distribution of ABO types in patients with diabetes mellitus. Anthropologist 2008;10(2):129-32.

[20] Kamil M, Al-Jamal HA, Yusoff NM. Association of ABO blood groups with diabetes mellitus. Libyan J Med 2010;5(1):4847-51.

[21] Okon UA, Antai AB, Osim EE, et al. The relative incidence of diabetes mellitus in $\mathrm{ABO} /$ Rhesus blood groups in South-Eastern Nigeria. Niger J Physiol Sci 2008;23(1-2):1-3.

[22] Whiteman H. Type 2 diabetes risk may be influenced by blood type. Medical News Today. Published on Mon 22 Dec, 2014.

[23] Maehr G. Distribution of ABO blood groups in diabetes mellitus. Wein Klin Wochenschr 1959;71:536-8.

[24] Craig J, Wang I. Blood groups in diabetes mellitus. Glasgow Med J 1955;36(8):261-6.

[25] Qureshi MA, Bhatti R. Frequency of ABO blood groups among the diabetes mellitus type II patients. J Coll Physician Surg Pak 2003;13(8):453-5.

[26] McConnell R, Pyke DA, Roberts JAF. Blood groups in diabetes mellitus. Br Med J 1956;1(4970):772-6.

[27] Andersen J, Lauritzen E. Blood groups and diabetes mellitus. Diabetes 1960;9(1):20-4.

[28] Henry MU, Poon-King T. Blood groups and diabetes. West Ind Med J 1961;10:156-60.

[29] Tedeschi G, Cavazzuti F. Contribto casistico allo studio dei rapporti tra diabete mellito e gruppi sanguigni. 
[Casuistic contribution on the study of the relations between diabetes mellitus \& the $\mathrm{ABO} \& \mathrm{Rh}$ blood groups]. $\mathrm{ABO}$ and Rh. Prog Med (Napoli) 1959;15(3):76-82.
[30] Gupta M, Singh N, Verma S. South Asians and cardiovascular risk: What clinicians should know? Circulation 2006;113(25):e924-e9. 